\title{
Relationship between Alcohol Use Disorder and Cognitive Reappraisal Among Youth Seeking Help in Rehabilitation Centers in Kiambu County, Kenya
}

\author{
Katembu Stephen \\ Department of Psychology \\ University of Nairobi, Kenya
}

Okunya Luke Odiemo (Corresponding author)

Department of Psychology

University of Nairobi, Kenya

Received: May 9, 2018 Accepted: June 27, 2018 Published: July 25, 2018

doi:10.5296/ijld.v8i3.13417ＵRL: https://doi.org/10.5296/ijld.v8i3.13417

\begin{abstract}
Alcohol is a widely used and abused substance globally. Deficits in cognitive reappraisal ability are assumed to mark the onset, maintenance, and relapse to alcohol use disorder. Alcohol may therefore be a means to escape from and self-medicate painful inner emotional states. The purpose of this study was to explore the relationship between and alcohol use disorder and cognitive reappraisal among youth seeking help in rehabilitation centers in Kiambu county. To establish any such relationships, this study utilised the Emotion Regulation Questionnaire (ERQ), and the Alcohol Use Disorder Identification Test (AUDIT). Data was collected from 33 (23Males/10Females) youths between 15-35 years seeking help in three rehabilitation centers for alcohol abuse. These youths were compared to a similar group of 33 (20 Females/13Males) youths who had never used alcohol, or any other substance of abuse, and 12 (8 Females/4 Males) others who had stayed alcohol free for at least three years after rehabilitation or quitting alcohol. Correlation research design was found appropriate for this study. A Pearson's correlation coefficient indicated a negative and significant correlation between AUD and reappraisal, showing that inability to utilise reappraisal is related to AUD. Integrating adaptive emotion regulation skills training, and especially the use of cognitive reappraisal in healthcare and rehabilitation settings, it seems, may lead to higher success rates in rehabilitation.
\end{abstract}


Keywords: alcohol use disorder, cognitive reappraisal, emotion regulation

\section{Introduction}

Alcohol is a common drink in many cultures consumed mainly for recreational purposes. For years that humans have drunk fermented beverages, a debate about their merits and demerits has persisted. From the medical perspective, alcohol has been associated with the dangerous health problems such as liver cirrhosis and alcohol hepatitis among others (Rehm, 2011). Despite the strong evidence for discouraging alcohol consumption, its production and use still persists on the economic and social ground (Murphy, Roberts, Stickley, \& Mckee, 2012).

On one hand it is recommended that light-to-moderate alcohol consumption has been found to be good for the heart and circulatory system (Goldberg, Mosca, Piano, \& Fisher, 2001). This is associated with reduced cardiovascular deaths, and reduced clot-related (ischemic) stroke. Ischemic stroke is explained by findings that moderate drinking increases high-density lipoprotein cholesterol ('good' cholesterol), reduces plasma viscosity, decreases platelet aggregation and has antioxidant effect (Goldberg et al., 2001; Kloner \& Rezkalla, 2007). This reduces the possibility of a clot.

Unrestrained consumption of alcohol causes health problems which culminate into social and economic burden in societies (Centre for Disease Control and Prevention, 2018; World health Organization (WHO), 2014). In 2012 alone, 5.9\% (3.3 million) deaths and 5.1\% (139 million) of all diseases and injuries worldwide were attributable to harmful use and abuse of alcohol (WHO, 2014). Studies conducted by World Cancer Fund and American Institute for Cancer Research (World Cancer Fund and American Institute for Cancer Research, 2007) found that alcohol use among men is positively correlated with cancer of the mouth, pharynx, larynx, esophagus, breast, colon and rectum. In women, it was linked to liver and colorectal cancer.

Researchers on alcoholism are yet to agree on how much alcohol constitutes unhealthy consumption (Kloner \& Rezkalla, 2007). According to the U.S. Department of Agriculture and U.S. Department of Health and Human Services Dietary (2005), one drink a day is considered moderate. That translates into either 12 ounces of beer, 5 ounces of wine, or 1.5 ounces of spirits and other hard liquors as gin or whisky, translating to 12-14 grams of pure alcohol. The latest consensus places moderate drinking at 2 drinks per day for men and 1 drink per day for women. Anybody consuming more than this is considered to be suffering from Alcohol Use Disorder (Samokhvalov, Rehm, \& Roerecke, 2015)

The Diagnostic and Statistical Manual of Mental Disorders (DSM), $5^{\text {th }}$ edition (APA, 2013), integrated 'alcohol abuse and alcohol dependence,' into one and called it Alcohol Use Disorder (AUD). It further classifies alcohol use disorder into; mild, moderate, and severe. AUD involves problematic patterns of alcohol use which causes significant clinical impairments or distress. Individuals with AUD are identified by the length of time put in efforts to obtain and use alcohol, which they take in larger amounts than intended. Such efforts are followed by unsuccessful attempts to reduce or quit alcohol use. People with AUD, despite the social or interpersonal problems that come with it, continue to satisfy their deep craving for alcohol. Tolerance increases with time, and more alcohol is required to produce the effects that 
were previously produced by lesser amounts. Efforts to quit are hampered by the reinforcing need to take alcohol to relieve the pain of withdrawal symptoms (APA, 2013).

Several factors have been found to cause alcohol abuse. They include Genetic predisposition (Begleiter \& Porjesz, 1999), heavy maternal drinking during pregnancy, being raised by alcoholic parents (Baer, 2003), influence from immediate drinking peers (Arata, Stafford, \& Tims, 2003), increases in stress levels from the demands of academics for those in school (Lorente, Peretti-watel, Griffet, \& Grelot, 2003), Attention Deficit/Hyperactivity Disorder (ADHD) and/or conduct disorders in men, and women suffering from depression, anxiety, and those who suffered social avoidance as children (Frone, Russell, \& Cooper, 1993).

Besides the above mentioned predisposing factors, the lack of control in alcohol consumption has been largely attributed to the socio-cultural setting of an individual. A comparative study on drinking habits was conducted in Europe and the United States of America (USA) by Friese, Grube, Seninger, Paschall and Moore (2011). They found that youths in the USA tend to abuse alcohol in comparison to their European counterparts. They explained that alcohol drinking in Europe begins in cultural contexts where young people are encouraged to drink within the family setting with an assumption that this will encourage moderate drinking in future. On the contrary, in the USA, the legal drinking age of 21 years restricts parents from socializing their children into the culture of moderate drinking. This has been found to cause young Americans below 21 years of age to start drinking outside the family setup without any socialization about the value of moderate alcohol consumption. They therefore, end up experiencing more alcohol related problems their European counterparts (Grube et al., 2011).

In Kenya, as it is in most African countries, alcohol use is rooted in early cultural practices where it was the main drink during special occasions like weddings, initiation ceremonies, and meetings of elders (Basangwa et al., 2006). There were however clear guidelines on alcohol consumption. For example, women, youth and children not were allowed to drink (Birech, Kariuki, Misaro, \& Kabiru, 2013). Such guidelines for moderate drinking in most Kenyan cultures seem to have been shredded by modernity as youths and minors abuse alcohol with impunity (Psirmoi, 2015).

From family history to emotionally potent circumstances, factors that have been associated with alcohol use and abuse seem to come with them an emotional load that requires the appropriate ways to bear. Inability for one to effectively regulate such emotive states and/or their day-to-day emotion eliciting situations might be a predisposing factor in the onset and maintenance of alcohol use and abuse. This makes emotion regulation an important factor in the development of AUD. Negative life events trigger emotions which guide behavior responses; with the type of behavior response being informed by the manner in which emotion regulation is employed (Mohajerin, Dolatshahi, Shahbaz, \& Farhoudian, 2013).

Emotion regulation describes the 'process by which individuals influence the kind emotions they have, when they have them, how they experience and express them' (Gross, 1998, p. 275). It is the process through which individuals consciously or unconsciously modulate their emotions (Gross \& John, 2003) to meet environmental demands (Nolen-Hoeksema \& Aldao, 2011). 


\section{MInstitute Macrothink $_{\text {Ins }}$}

Research that explicitly focuses on emotion regulation began first in developmental psychology (Gaensbauer, 1982). It is currently focused on children as much as among adults (Gross, 1998). Whereas an emotion eliciting situation may cause short lived changes in the behavioral, experiential, autonomic, and neuroendocrine systems, it is how such emotion responses are modulated that determines the outcome of an emotional event (Gross, 1998).

Deployment of emotion regulation strategies aim at modifying the magnitude of an affective state, and alter its experience or expression (Gross, 1998). An association between successful emotion regulation and well-being has been made by theoretical models of emotion regulation (John \& Gross, 2004). Further research has demonstrated that individuals who do not effectively manage such emotional responses in their day-to-day stressful life events are likely to be more distressed, evolving into diagnosable psychopathologies such as anxiety and depression (Nolen-Hoeksema \& Aldao, 2011).

Individuals seeking help with alcoholism have been found to exhibit maladaptive regulation of negative emotions, while adaptive emotion regulation strategies have been found to moderate between negative emotions and craving for alcohol (Berking et al., 2011). The implication here is that individuals unable to deal with their impulses may find alcohol an effective way to reduce negative impulses, albeit temporarily. More alcohol may be taken to deal with emotions later when they arise leading to alcohol abuse.

With a wide range of emotion regulation strategies, it is of paramount importance to identify which strategy is more effective in emotion regulation and make it the one of choice in a wide range of emotion-eliciting scenarios. The success of an emotion regulation strategy depends on the time it is utilised. That is, when the strategy has its primary impact on the emotion-generating process (Urry, 2009).

Depending on the timing, there are two classes of emotion regulation strategies; antecedent focused and response-focused strategies (Gross, 2002). Antecedent focused affect regulation strategies precede full stimulation of the emotion responses during the emotion eliciting situation, and tends to modify the entire course of an emotion response (Gross, 2002). It should therefore be an effective strategy in down-regulating emotions (Urry, 2009).

Response-focused strategies on the other hand engage inhibition to decrease emotion-expressive behavior during an emotion-generating situation (Mohajerin, Dolatshahi, Shahbaz, Farhoudian 2013). This strategy is implemented when emotion responses are fully underway and with expressive behaviour fully operationalized, weighing heavily on individual's inner resources to regulate (Gross, 2002).

Antecedent strategies such as cognitive reappraisal, unlike response focused strategies such as expression suppression, reduce the inner experience and outward expression of emotions and decreases the behavioural expression of responses due to inner emotional states (Gross, 2002). Whereas there are several strategies that an individual can apply to moderate situations that may elicit negative affect, the preceding literature seems to point to the conclusion that cognitive reappraisal is more effective in successful emotion regulation due its adaptability advantage over the others in decreasing or increasing affective states. (Gross, 2002; Mohajerin, 
Dolatshahi, Shahbaz, \& Farhoudian, 2013).

The Cognitive Appraisal theory (Lazarus \& Folkman, 1984), describes Cognitive appraisals as mental process that influences how stressors are reacted to; adaptively or maladaptively. This theory posits that emotions are only a manifestation of a prior evaluation of person-environment relationships involving a given harm or benefit. Emotional reactions are therefore, seen as dependent on what a given affect eliciting situation means to personal well-being. This theory posits that thought is a key adaptation process intervening between environmental challenges and actions. These cognitive activities that evoke emotional responses are, in this theory, referred to as appraisals; i.e., the processes by which events or situations in an individual's environment are judged as good or bad (Lazarus \& Folkman, 1984). Just as James-Lange could not conceive an emotion without a body, Lazarus and Folkman (1984) could not conceive of an emotion without its corresponding appraisal.

Appraisal happens in three levels. At the primary appraisal stage, the significance of an event is established and given meaning. The emotion evoking situation is then categorized as positively significant, stressful, relevant or irrelevant to well-being. Secondary appraisal follows primary appraisal, as one's assessment of their capacity to handle the consequences of the event. Available resources to cope with the situation are accounted at this stage, the reappraisal follows the emotive event, and available coping resources are monitored, and if necessary modified to adaptively deal with the situation (Gross, 1998)

An individual's mental evaluation of what is happening, what it means, and how significant the happening is to them (appraisal), has been found to directly determine emotional state and hence wellbeing (Lazarus \& Folkman, 1984). Mechanisms behind these processes are debatable. They can happen simultaneously, and sometimes the secondary appraisal happens first. The quality and intensity of an emotion is therefore cognitively determined. It is these appraisals that mediate between the individual, the emotion eliciting event, and their ability to cope, hence their reactions. Further, Appraisals can be automatic (unconscious, without individual's awareness of volitional control) or conscious (deliberate and volitional) (Lazarus, 1991). Appraisals may involve very rapid associative processes that mostly occur below the level of conscious awareness, (Smith \& Kirby, 2001), but as can be seen from the above three level analogy, the most probable stage at which an individual can consciously be involved is at the reappraisal stage, where besides monitoring the situation and available coping resources, it's possible to modify appraisals to extract favorable mood states, motivate adaptive behaviour, socially acceptable action, and avoid possible harm.

Appraisal theories therefore seem to be founded on the idea that emotions result from evaluation of stimuli, and that too forms the basis of how emotion reactions may be modified and hence regulated. These theories point to the fact that if an appraisal can be changed, then the mood state can be changed too, and so can the accompanying emotion reaction behaviours. It was found that how emotions are reacted to in the face of threatening situations can be 'short-circuited' by altering the way in which such situations are cognitively appraised (Lazarus \& Folkman, 1984). Positive psychotherapeutic outcomes are therefore possible through appraisal, as it significantly alters affective responses. 
When reappraisal is not well appropriated, maladaptive behaviours like the use of substances of abuse such as cocaine, alcohol, and cigarettes are sometimes used to down-regulate emotional experience (Gross, 2002). This is because much as the physiological and behavioural aspects of the emotion are suppressed, the individual continues to experience the emotion and may need something to calm them down. Clinically, drugs which target physiological changes have been used. They include anti-anxiolytics to reduce muscle tension or sympathetic hyperactivity (Gross, 1998).

With the goal of down-regulating emotions, reappraisal reduces the inner experience and outward expression of an emotional episode (Gross, 2002). Studies by Gross and John (2003) found that individuals who use reappraisal were highly adaptive, scored high on wellbeing and had less depression symptoms as compared to individuals who used other strategies. Commonly used and effective psychological interventions such as cognitive behavioral therapy (CBT), utilizes reappraisal as key ingredient (Troy, Wilheim, Shallcross, \& Iris, 2012). When subjects in experiments are overtly asked to employ the reappraisal technique, they have been found to experience less negative affect as compared to control groups using other strategies (Ochsner et al., 2004; Sheppes \& Meiran, 2007).

Reappraisal is an antecedent focused emotion regulation strategy in that it comes before the full activation of the emotion responses during the emotion eliciting situation, and tends to modify the entire course of an emotion response (Gross, 2002). It should therefore be an effective strategy in down-regulating emotions in a situation where others may opt to use alcohol in attempts to self-medicate inner affective states.

Difficulties in regulating the experience and expression of affective states has been associated with eating disorders, smoking, self-harm and addictions (Macklem, 2008), Alcohol abuse models too have found that one's ability to choose an adaptive emotion strategy over a maladaptive one is of importance. For instance, individuals who choose an adaptive emotion regulation strategy such as reappraisal experience positive mood states and self-esteem attributes that help regulate emotions and counteract everyday stressful life events (Brackett, Mayer, \& Warner, 2004). Individuals who deploy maladaptive strategies such as expression suppression may use alcohol in attempts to escape from down-regulation of their emotions (Kenneth \& Emily, 2007). It seems therefore that the choice of the right strategy might be of importance in reigning over the impulses that lead to drinking alcohol to self-medicate inner emotional distress. It is in the basis of this argument that the current study sought to explore how the deployment of cognitive reappraisal among participants under treatment for AUD compared with the deployment of the same strategy among individuals who had never used alcohol and those who have stayed alcohol free for at least a year after rehabilitation for AUD.

\section{Method}

\subsection{Research Design}

Correlation design was used to relate the independent variable to the dependent variable. The purpose was to establish a relationship between the variables in the study. 


\subsection{Participants}

Informed by the fact the target strata was not easily available and the fact that AUD is associated with some degree of stigma, the researcher employed snowballing technique to recruit participants between the ages of 15-35. The researcher recruited 33 (10 Female/23 Male) participants who abused alcohol, 33 (20 Female /13 Male) who had never taken alcohol or any other drug, and only 12 ( 8 Female $/ 4$ Male) individuals who had successfully gone through rehabilitation and had stayed alcohol free for at least a year. Majority of respondents were male (64\%), with the modal age bracket being 20 to 25 years (44\%). Most of the participants had at least a university degree (35\%), were single (63\%), and had both parents $(70 \%)$. People who had abused any other substance other alcohol and those suffering from psychiatric problems were excluded. All participants signed an informed consent, and were assured of confidentiality of their responses. The study was approved by Kenya's National Commission for Science, Technology, and Innovation (NACOSTI).

\subsection{Materials}

A questionnaire with four sections was utilised. The first part collected background information to indicate participant's characteristics. To identify the extent to which individuals abused alcohol, the Alcohol Use Identification Test (AUDIT) was used. This instrument that was developed by WHO and tested on participants drawn from six countries, among them, Kenya, has been found to be an effective trans-cultural screening tool for screening for alcohol use and dependency among participants in health care settings (WHO, 2004). Further studies have psychometrically proven that AUDIT is a sound instrument for detecting alcohol abuse among adolescents, college students, young adults, women, and individuals drawn from minority groups not only in health care contexts but also in community settings (Meneses-Gaya et al., 2009).

The AUDIT consists of 10 items, with a zero to four (0-4) scoring scale. Frequency of alcohol use behaviours are tested by six out of the ten questions. The questions are such as "How often during the last year have you found that you were not able to stop drinking once you had started?" "How often during the last year have you been unable to remember what happened the night before because you had been drinking?" and "How often during the last year have you failed to do what was normally expected from you because of drinking?" These questions, which fit in very well with DSM-V description of how AUD is diagnosed were responded to as "Never" (0), "Less than monthly" (1), "Monthly" (2), "Weekly" (3), and "Daily or almost Daily" (4). Questions 1 to 3 measured the frequency of drinking. Questions 4 to 6 detected alcohol dependency while questions 7 to 10 were a measure of alcohol related problems, all with a score of 0-4 points. After responding to the questionnaire, all the points were added to get a score for each participant. Eight (8) or more points in men, and seven (7) or more points in women was an indicator of risky or harmful alcohol use, while a score of twenty (20) and above was indicative of alcohol dependency.

Psychometric studies by Maneses-Gaya and others (2009) found a high validity of the AUDIT in detection of AUD among university students. It was also found to be high in sensitivity $(0.67)$, specificity $(0.96)$, and positively predictive $(0.75)$. This instrument was therefore ideal 
for the current study.

In order to test the emotion regulation strategies employed by participants, the reappraisal scale of the Emotion Regulation Questionnaire (ERQ) was used. This scale consists of 6 items $(1,3,5,7,8,10)$. In a scale of 1 to 7 , where 1 is 'Strongly disagree' and 7 is 'Strongly Agree', participants were required to rate how they regulate their emotions. The mean scores of the subscales are calculated and used to rate the extent to which an individual utilizes reappraisal. A high score reflects a great extent of strategy deployment while regulating inner emotion states. Gross and John (2003), reported an acceptable Cronbach's alpha coefficient reliability value of .79 for the reappraisal subscale. Checked for intercorrelations, the reappraisal subscale was found to be mildly and insignificantly $(\mathrm{rs}<0.7)$ intercorrelated with the suppression scale

\subsection{Data Collection}

The researcher visited rehabilitation centers in Kiambu County for a familiarization meeting with the directors, counselors and social workers. The benefits of the research to the centers were explained to the authorities. It was confirmed in this meeting that the centers had individuals who were abusing alcohol and not any other drug, and that they were still in touch with individuals who had stayed for at least a year after rehabilitation from alcohol abuse. A date was then set for the researcher to meet the refereed participants. The researcher also requested the participation of the workers between the ages of 18-35 who had never used alcohol and other drugs (abstainers). This category of abstainers did not have as many people in the rehabilitation centers, and therefore those who participated were requested to inform other abstainers in the community to join study as participants.

On the set day for data collection, the researcher met the participants at times convenient for the different rehabilitation centers. The instruments were then administered after brief instructions on how to fill the questionnaires. The participants took about 20 minutes to respond to the questionnaire.

\subsection{Data Analysis}

Data obtained using these instruments was first coded and entered into excel spreadsheets for cleaning before analyzing with the Statistical Package for Social Sciences (SPSS). Summary of data and participant characteristics were presented using descriptive statistics. The results of this study were computed in accordance with the study objective, and where applicable, descriptive statistics were given. In order to test the study hypothesis, inferential statistics were computed.

\section{Results}

Majority of abstainers (54\%) were between ages 20 to 25, while among majority (52\%) of those with AUD were in the age between 31-35 years. The age 15-19 only had one participant. Although there were no clear patterns in the way reappraisal was utilised across the different ages groups, scores indicated that individuals in the 31-35 age bracket reappraised the least (4.4), and had the highest AUD prevalence. Those who abstain were 5.0. Individuals who had gone through rehabilitation and stayed alcohol free for at least a year did not differ from 


\section{Macrothink}

International Journal of Learning and Development

ISSN 2164-4063 2018, Vol. 8, No. 3

lifetime abstainers in their deployment of cognitive reappraisal. It therefore seems that indeed, reappraisal is an important mediator in alcohol abuse in that it may prevent the use of alcohol in dealing with negative affective states.

AUD prevalence was more among men than among women (see Figure 1). Average scores on the reappraisal scale of the ERQ among abstainers were 5.2 and 5.3 for men and women respectively. Men and women with AUD had 4.8 score of reappraisal. So as much as the scores were similar, those with AUD had lower scores compared to abstainers.

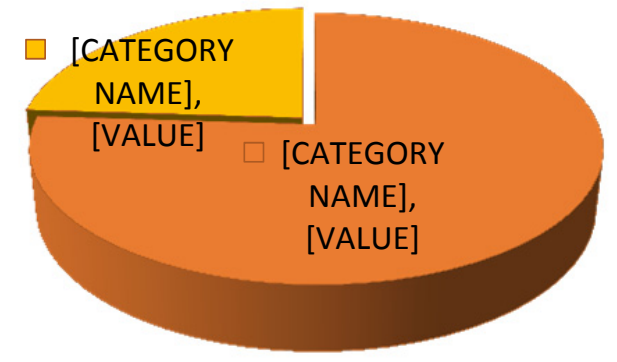

Figure 1. AUD prevalence and gender

A Pearson's correlation coefficient test revealed correlation between gender and reappraisal as presented in Table 1 below. Being male for was negatively correlated to reappraisal $(\mathrm{r}=-0.041$, $\mathrm{n}=77, \mathrm{p}=0.723$ ). On the other hand, being female was positively correlated to reappraisal $(\mathrm{r}=0.41, \mathrm{n}=77, \mathrm{p}=0.723)$. It was also found that men were positively but weakly correlated to AUD ( $\mathrm{r}=0.154, \mathrm{n}=77, \mathrm{p}=0.178)$, while women were negatively and weakly correlated to AUD $(\mathrm{r}=-0.154, \mathrm{n}=77, \mathrm{p}=0.178)$.

Table 1. Results of pearson's bivariate correlation test

\begin{tabular}{llll}
\hline \multirow{2}{*}{ Male } & & Reappraisal & AUDIT \\
& Pearson Correlation & -.041 & .154 \\
\cline { 2 - 4 } & Sig. (2-tailed) & .723 & .178 \\
\hline \multirow{2}{*}{ Female } & Pearson Correlation & .041 & -.154 \\
\cline { 2 - 4 } & Sig. (2-tailed) & .723 & .178 \\
\hline
\end{tabular}

Note. $\mathrm{N}=77, * *$. Correlation is significant at the 0.01 level (2-tailed).

Participants in this study were drawn from Catholic (45\%) and Protestant $(55 \%)$ religious orientations. Among the participants with a zero (0) score on the AUDIT, 37\% were Catholics, and $63 \%$ were Protestants. 


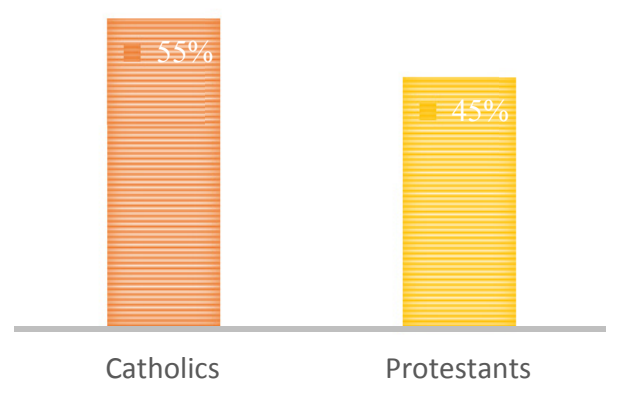

Figure 2. AUD and religious orientations

Results for cognitive reappraisal scores in this study found that Catholic participants recorded lower scores (4.7) compared to the Protestants (4.9).

A Pearson's correlation results showed that being a Catholic and reappraisal $r(77)=-0.116$ have a weak negative relationship while being a protestant and cognitive reappraisal $r$ (77) $=0.116$ have a weak but positive relationship. Further, Catholics were weakly but positively correlated to AUD $(n=77, r=0.167)$ while protestants were negatively but weakly correlated to AUD $(r=-0.167)$.

Table 2. Results of Pearson's Bivariate Correlation Test across religion

\begin{tabular}{llll}
\hline & & Reappraisal & AUDIT \\
\hline \multirow{2}{*}{ Catholic } & Pearson Correlation & -.116 & .167 \\
& Sig. (2-tailed) & .313 & .145 \\
\hline \multirow{2}{*}{ Protestant } & Pearson Correlation & .116 & -.167 \\
& Sig. (2-tailed) & .313 & .145 \\
\hline
\end{tabular}

Note. $\mathrm{N}=77,{ }^{* *}$ Correlation is significant at the 0.01 level (2-tailed).

Abstainers from families with both parents, and scored 5.3 in Reappraisal, while those reported that they had been brought up by single mothers scored the highest in reappraisal (5.7) compared to those brought up by single fathers reported a reappraisal score of 4.0.

Of those who had AUD, 19\% were brought up by single mothers, $28 \%$ were brought up by single fathers, $21 \%$ had both parents and $32 \%$ had been orphaned. However, checked on account of emotion regulation strategies used, it was found that participants who had been orphaned recorded the highest prevalence of AUD (32\%) and had the highest score in the reappraisal scale of the ERQ (5.2), while those who had been brought up by single fathers recorded the lowest scores in reappraisal (3.9), and a AUD prevalence of $28 \%$. 


\section{Macrothink}

International Journal of Learning and Development

ISSN 2164-4063 2018, Vol. 8, No. 3

Table 3. Composite average scores for cognitive reappraisal among across family history

\begin{tabular}{lllll}
\hline Family History & Single Mother & Single Father & Both Parents & Orphaned \\
\hline Cognitive Reappraisal & 4.7 & 3.9 & 5.0 & 5.2 \\
AUD Prevalence (\%) & 19 & 28 & 21 & 32 \\
\hline
\end{tabular}

Though there were no clear patterns of how reappraisal related to the prevalence of AUD vis-a-vis family background. A Pearson's correlation seemed to point in the direction that the family environment fostered a given emotional state. Individuals who had been brought up by both parents for example were positively, though weakly correlated to reappraisal, while the relationship between being brought up by a single father and reappraisal $r(77)=-0.268^{*}$ was negatively and significantly correlated to reappraisal. The other correlations were as in Table 4 below.

Table 4. Results of pearson's bivariate correlation test

\begin{tabular}{llllll}
\hline & & Single Mother & Single Father & Both Parents & Orphaned \\
\hline \multirow{2}{*}{ Reappraisal } & Pearson Correlation & -.053 & $-.268^{*}$ & .195 & .049 \\
\cline { 2 - 6 } & Sig. (2-tailed) & .647 & .018 & .089 & .670 \\
\hline
\end{tabular}

Note. $\mathrm{N}=77 * *$ Correlation is significant at the 0.01 level (2-tailed).

Majority of non-drinkers (64\%) were drawn from the lower middle class while the least were drawn from middle class (3\%). The low class was represented by $24 \%$, while $9 \%$ of respondents were from high class. This was replicated in the opposite direction in that $80 \%$ of individuals with AUD were drawn from the middle class while $18 \%$ were drawn from the lower middle class. The middle and lower classes in this study therefore seemed to abuse alcohol more that the upper classes (see Figure 3). There was no clear pattern of alcohol use and abuse across different social classes.

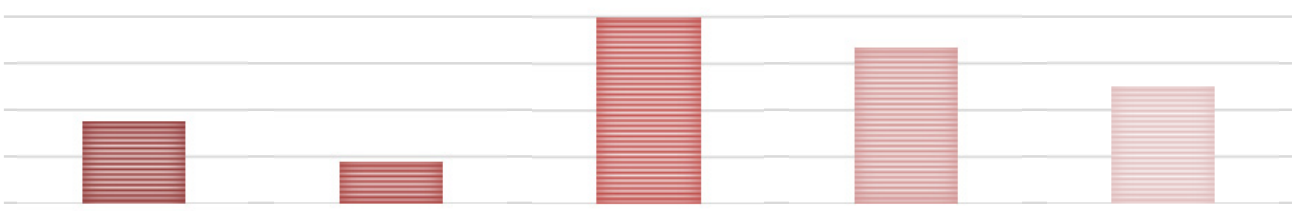

Figure 3. Prevalence of AUD across different socioeconomic groups 


\section{Ml Macrothink}

International Journal of Learning and Development

ISSN 2164-4063 2018, Vol. 8, No. 3

The use of cognitive reappraisal across the different socioeconomic groups was studied. Results indicated that individuals in the upper socioeconomic class reappraised the most (5.7) compared to those in the low class (4.8) (see Table 5). Whereas there doesn't seem to be a patterned use of reappraisal to account for the drinking pattern, this might be due to the fact that the incomes reported in the questionnaire were either of self or family since majority of the participants were in college going age of 20-25.

Table 5. Composite average scores for cognitive reappraisal at different socioeconomic classes

\begin{tabular}{llllll}
\hline Income Ksh (x1000) & $<19.999$ & $20-79.999$ & $80-139.999$ & $140-199.999$ & $>200$ \\
\hline Cognitive Reappraisal & 4.8 & 5.1 & 4.7 & 4.5 & 5.7 \\
AUD Prevalence (\%) & 35 & 18 & 80 & 67 & 50
\end{tabular}

Participants who had only gone up to secondary school level were found to abuse alcohol more that those who had proceeded tertiary institutions of learning. Among individuals with AUD, $63 \%$ had not proceeded to college, while only $17 \%$ individuals with AUD had a university degree (see Figure 4).

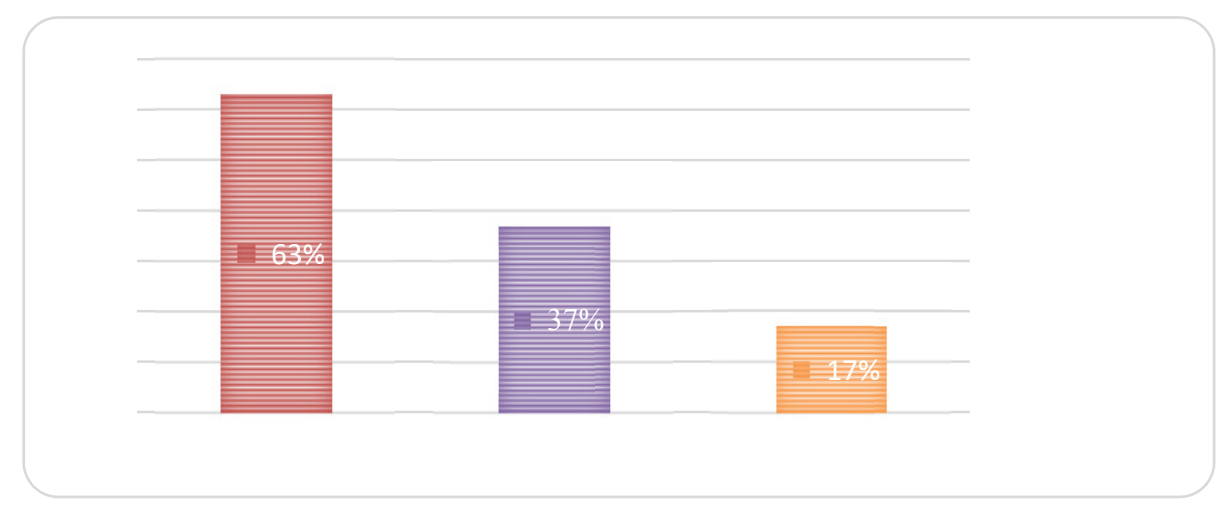

Figure 4. AUD and education level

In an attempt to trace the differences in the development of AUD among individuals at different education levels, the use of reappraisal as an emotion regulation strategy was studied. It was found that individuals who had only up to secondary school level utilized this strategy the least at 4.5 , followed by individuals who had college or university education who scored 4.9 as shown in Table 5. There seems to be a pattern in the prevalence of AUD among the different education levels as individuals with the least level of education recorded the lowest scores (4.5) in the use this adaptive strategy, and also, had the highest prevalence of AUD $(63 \%)$ (See Table 6) 
Table 6. Composite average scores for cognitive reappraisal at different education levels

\begin{tabular}{llll}
\hline Variable & Secondary & College & University \\
\hline Reappraisal & 4.5 & 4.9 & 4.9 \\
AUD prevalence (\%) & 63 & 37 & 17 \\
\hline
\end{tabular}

As illustrated in Table 7, individuals in rehabilitation centers whose AUDIT scores indicated they had alcohol dependency, scored the lowest in cognitive reappraisal strategy (4.3) compared to lifetime abstainers and individuals who had been out of rehabilitation and stayed alcohol free for at least a year, who scored high on cognitive reappraisal (5.1).

Table 7.Composite averages for cognitive reappraisal among individuals with AUD, the rehabilitated and lifetime abstainers

\begin{tabular}{llll}
\hline Variable & With AUD & Rehabilitated & Abstainers \\
\hline Cognitive Reappraisal & 4.3 & 5.1 & 5.0 \\
\hline
\end{tabular}

\section{Discussion}

The prevalence of alcohol use increased with increasing age peaking at ages 30 to 35 . This is confirmed findings by Makela (2006) that drinking frequency increased with age, and by Chesang (2013), that youth between the ages of 16 to 30 abused alcohol the most. The high deployment rate of reappraisal at age 26, and a lower use of this strategy as individuals approach 35 years is in tandem with other studies that have shown that the use of reappraisal is significantly related to age (McRae et al., 2012; Nolen-Hoeksema \& Aldao, 2011). This trend in AUD and reappraisal can be explained by studies that have showed that low cognitive reappraisal ability results in less psychological wellbeing, high anxiety and stress, and is positively correlated to maladaptive strategies in dealing with emotionally challenging situations, including alcohol and drug abuse (Troy, Wilheim, Shallcross, \& Iris, 2012). In this study, participants in the 31-35 age bracket reappraised the least, and had the highest AUD prevalence.

Men comprised $76 \%$ of those with AUD. This is in tandem with empirical study findings that Men abuse alcohol more than women, and as a result, they are at a greater risk of developing AUD (Makela, 2006; Schulte, Ramo, \& Brown, 2009; Parry, 2005). ERQ scores indicated that women utilised reappraisal more than men. This is in agreement with earlier studies showing that women use reappraisal to re-interpret negative situations in positive ways more than do their male counterparts (McRae et al., 2012; McRae, Ochsner, Mauss, Gabrieli, \& Gross, 2008; Nolen-Hoeksema \& Aldao, 2011). Being male for was negatively correlated to reappraisal and positively but weakly correlated to AUD. Men's low scored in reappraisal might be a contributing factor in male high rate of AUD as a maladaptive strategy to numb inner emotions 
(Khantzian, 1997).

Participants with AUD were mostly Catholics (55\%). This confirms previous studies that Catholics used alcohol more compared to individuals from other religious orientations (Mullen, Williams, \& Hunt, 1996). This could be attributed to the fact that Catholics are more accommodative of alcohol use compared to protestants, and therefore have increased risks of developing AUD (Engs \& Mullen, 1999). Further, religion has been positively correlated to adaptive self-regulation skills especially cognitive reappraisal (McCullough and Willoughby, 2009), a strategy which has been shown to lessen the likelihood of an individual's engagement in alcohol abuse when dealing with negative emotional states (Gross \&John 2003). Catholics had lower cognitive reappraisal scores, a likely explanation why this study found a positive correlation between reappraisal and AUD.

Majority of participants who had never used alcohol or any other drug were from families with both parents, and scored the highest in the reappraisal scale. Similar findings have indicated that parental care of both parents models an emotional environment fosters adaptive emotional reaction, with children brought up in a caring family environment utilizing cognitive reappraisal more often even as adults, compared to children or adults brought up in a less caring family environment (Gunzenhauser, Fäsche, Friedlmeier, \& von Suchodoletz, 2014; Morris, Silk, Steinberg, Myers, \& Robinson, 2007; Gross \&John, 2002). It was however interesting to find that participants who had been brought up by single mothers had the highest reappraisal scores. This further confirms studies that women utilised reappraisal more (McRae et al., 2012; McRae, Ochsner, Mauss, Gabrieli, \& Gross, 2008; Nolen-Hoeksema \& Aldao, 2011), and that the parent(s), and the family environment modelled emotion regulation strategy employed by the children (Gross \& John, 2002) Thus, the findings that AUD was least prevalent among participants brought up by single mothers seems to confirm that reappraisal could mitigate the use and abuse of alcohol. However, the findings that orphaned individuals scored very high cognitive reappraisal scores need to be investigated further.

Whereas some studies have shown that young people from higher SES families use alcohol more often and in more quantities compared to those of low SES (Schulenberg \& Patrick, 2012 ), the current study found that majority of non-drinkers (64\%) were drawn from the lower middle class, while majority (84\%) of those with AUD were drawn from the middle class. Results are conflicted on the relationship between the SES and alcohol use and abuse (Patrick, Wightman, Schoeni, \& Schulenberg, 2012). Further, although individuals in the upper socioeconomic class reappraised the most (5.7) compared to those in the low class (4.8), there was no patterned use of reappraisal to account for the drinking pattern. This might be attributable to the fact that the incomes reported in the questionnaire were either of self or family since majority of the participants were college going. It might also be explained by other confounding variables such as family background, culture and religious beliefs.

The findings that participants who had only gone up to secondary school level were found to abuse alcohol more that those who had proceeded to tertiary institutions of learning were in tandem with findings that low education was positively correlated to frequent and heavy drinking (Crum, Helzer, \& Anthony, 1993; Schnohr, Hojbjerre, Riegels, Ledet, Larsen, 
Schultz-Larsen, \& Gronbaek, 2004). Findings on emotion regulation strategies showed that individuals who had only up to secondary school level utilized reappraisal the least (4.5) followed by individuals who had college or university education. Whereas there is a dearth of studies on what it is in education that determines the level of risk developing AUD. There is a likelihood that educated people have a cognitive advantage over the less educated individuals and are likely to deal with internal and external emotional pressures better. They may also appraise themselves as able, compared to the less educated folk. This may explain the differences in the use of reappraisal, a strategy that deals with affective situations in a way that doesn't predispose individuals to maladaptive mannerisms such as alcohol abuse to deal with emotional states unresolved (Khantzian, 1997).

Even with the above confounding variables, a Pearson's correlation confirmed reappraisal is negatively correlated to AUD. These findings confirmed by earlier experimental and correlation study findings that cognitive reappraisal mitigates the development of maladaptive behavioural responses such as alcohol use when one is confronted by emotionally arousing situations (Stappenbeck \& Fromme, 2014). Further, compared to nonsmokers, smokers scored low on the reappraisal scale, and smoked with expectations that it would help them manage negative feelings (Fucito, Juliano, \& Toll, 2010).

According to Appraisal theories (Lazarus \& Folkman, 1984) if an appraisal can be changed, then the mood state can be changed, and so can the accompanying emotion reaction behaviours. Lazarus and his students found that how emotions are reacted to in the face of threatening situations can be 'short-circuited' by altering the way in which such situations are cognitively appraised (Lazarus \& Folkman, 1984). Positive psychotherapeutic outcomes are therefore possible through appraisal, as it significantly alters affective responses. This explains why reappraisal in this study is negatively associated with AUD.

\section{Conclusions}

All factors held constant, emotion regulation strategy of reappraisal seems to play role in the development and maintenance of AUD. There was a negative and a significant relationship between the use of cognitive reappraisal and AUD. It should however, be noted that the current study did not establish any causal relationships between AUD and reappraisal. It would be important to carry out a study over a long period and follow up participants to see how those who developed AUD reappraised before AUD. Further, it would be important for future studies to explore other ways in which cognitive reappraisal inability may manifest as maladaptive responses besides AUD, and the role personality plays in informing the manner in which individuals regulate their day to day affective situations.

\section{References}

American Psychiatric Association. (2013). Diagnostic and Statistical Manual of Mental Disorders: DSM-5. Washington, D.C: American Psychiatric Association. https://doi.org/10.1176/appi.books.9780890425596

Arata, C., Stafford, J., \& Tims, M. (2003). High school drinking and its consequences. Adolescence 38(151), 567- 579. PMID: 14768998 
Baer, R. (2003). Mindfulness training as clinical intervention: A conceptual and empirical review. Clinical Psychology: Science and Practice, 10(2), 125-143. https://doi.org/10.1093/clipsy.bpg015

Basangwa, D., Ndetei, M., Kuria, M., Ongecha-Owuor, F., Abdullahi, A., Mburu, J., \& Gakinya, B., (2006) "Alcohol and Other Substance Related Disorders". In D. M. Ndetei (ed.) African textbook of Clinical Psychiatry and Mental Health. Nairobi: Africa Medical Research Foundation, p. 228-253

Begleiter, H., \& Porjesz, B. (1999/2006). What is inherited in the predisposition toward alcoholism? A proposed model. Alcohol Clinical and Experimental Research, 23(7), 1125-1135. https://doi.org/10.1111/j.1530-0277.1999.tb04269.x

Berking, M., Margraf, M., Ebert, D., Wupperman, P., Hoffman, G., \& Junghanns, K. (2011). Deficits in emotion regulation skills predict alcohol use during and after cognitive behavior therapy for alcohol dependence. Journal of Consulting and Clinical Psychology, 79(3), 307-318. https://doi.org/10.1037/a0023421

Birech, J., Kariuki, K., Misaro, J., \& Kabiru, J., (2013).Alcohol Abuse and the Family: A Case Study of the Nandi Community of Kenya. International Journal of Humanities and Social Science, 3(15), 137-144. https://doi.org/10.1016/S0191-8869(03)00236-8

Brackett, M., Mayer, J., \& Warner, R. (2004). Emotional intelligence and its relation to everyday behavior. Personality and Individual Differences, 36(6), 1387-1402. https://doi.org/10.1016/S0191-8869(03)00236-8

Centre for Disease Control and Prevention. (2018). Fact Sheets - Alcohol Use and Your Health. https://www.cdc.gov/alcohol/fact-sheets/alcohol-use.htm.

Chesang, R. K. (2013). Drug Abuse Among the Youth in Kenya. International Journal of Scientific and Technology Research. 2(6), 126 -131. ISSN 2277-8616

Crum, M., Helzer, E., \& Anthony, C. (1993). Level of education and alcohol abuse and dependence in adulthood: a further inquiry. American Journal of Public Health, 83(6), 830-837. PMCID:PMC1694736 https://doi.org/10.2105/AJPH.83.6.830

Engs, C., \& Mullen, K. (1999). The Effect of Religion and Religiosity on Drug Use Among a Selected Sample of Post-Secondary Students in Scotland. Addiction Research, 7(2), 149-170. https://doi.org/10.3109/16066359909004380

Friese, B., Grube, W., Seninger, S., Paschall, I., \& Moore, S. (2011). Drinking Behavior and Sources of Alcohol: Differences Between Native American and White Youths. Journal of Studies on Alcohol and Drugs, 72(1), 53-60. PMCID:PMC3001681 https://doi.org/10.15288/jsad.2011.72.53

Frone, R ., Russell, M., \& Cooper, L. (1993). Relationship of work-family conflict, gender, and alcohol expectancies to alcohol use/abuse. Journal of Organizational Behavior, 14, 545-548. https://doi.org/10.1002/job.4030140604 


\section{Macrothink}

International Journal of Learning and Development

ISSN 2164-4063

2018, Vol. 8, No. 3

Fucito, M., Juliano, M., \& Toll, A. (2010). Cognitive reappraisal and expressive suppression emotion regulation strategies in cigarette smokers. Nicotine Tobacco Research, 12 (11), 1156-1161. https://doi.org/10.1093/ntr/ntq146

Goldberg, J., Mosca, L., Piano, R., \& Fisher, A. (2001). Wine and your heart: a science advisory for healthcare professionals from the Nutrition Committee, Council on Epidemiology and Prevention, and Council on Cardiovascular Nursing of the American Heart Association, Circulation, 103(3), 472-475. PMID: 11157703 https://doi.org/10.1161/01.CIR.103.3.472

Gross, J. J. (1998). The Emerging Field of Emotion Regulation: An Integrative Review. Review of General Psychology, 2, 271-299. https://doi.org/10.1037/1089-2680.2.3.271

Gross, J. J. (2002). Emotion Regulation: Affective, cognitive, and social consequences. Psychophysiology, 39 (3), 281-291. https://doi.org/10.1017/S0048577201393198

Gross, J. J., \& John, O. P. (2003). Individual differences in two emotion regulation processes: implications for affect, relationships, and well-being. Journal of Personality and Social Psychology, 85(2), 348-362. https://doi.org/10.1037/0022-3514.85.2.348

Gunzenhauser, C., Anika F., Wolfgang F.,\& Antje, V. (2014): Face it or hide it: parental socialization of reappraisal and response suppression. Frontiers in Psychology 4, (992), 1-14. https://doi.org/10.3389/fpsyg.2013.00992

Heath, B. (2001). Culture and Substance abuse. Cultural Psychiatry: International Perspectives, 24 (3), 479-496. https://doi.org/10.1016/S0193-953X(05)70242-2

Hassan, N. (2013). Factors Associated With Alcohol Abuse among University of Nairobi. Unpublished Thesis. University of Nairobi repository

Kenneth, S., \& Emily, R. (2007). Alcohol and Affect Regulation. In J. J. Gross (ed), Handbook of Emotion Regulation, New York: Guilford Press, 560-580.

Khantzian, E. J. (1997). The Self-Medication Hypothesis of Substance Use Disorders: A Reconsideration and Recent Applications. Harvard Review of Psychiatry, 4(5), 231-244. https://doi.org/10.3109/10673229709030550

Kloner, R., \& Rezkalla, H. (2007). To drink or not to drink? That is the question. Circulation, 116(11), 1306-17. https://doi.org/10.1161/CIRCULATIONAHA.106.678375

Lazarus, R., \& Folkman, S. (1984) Stress, Appraisal, and Coping. New York, NY: Springer.

Lazarus, R. (1991). Emotion and Adaptation. New York, NY: Oxford University Press.

Lorente, D., Peretti-watel, J., Griffet, J., \& Grelot, L. (2003). Alcohol use and intoxication in sport university students. Alcohol and Alcoholism, 38(5): 427-430. https://doi.org/10.1093/alcalc/agg105

Macklem, G. (2008). Practitioners guide to emotion regulation in school-aged children. New York, NY:Springer.

Mäkelä, P., Gmel, G., Grittner, U., Kuendig, H., Kuntsche, S., \& Bloomfield, K. (2006). 
Drinking patterns and their gender differences in Europe. Alcohol and Alcohol Addiction, 41(1), i8-18. https://doi.org/10.1093/alcalc/ag1071

McCullough, E., \& Willoughby, B. (2009). Religion, self-control, and self-regulation: Associations, explanations, and implications. Psychological Bulletin, 135(1), 69-93. https://doi.org/10.1037/a0014213

McRae, K., Ochsner, K., Mauss, I., Gabrieli, J., \& Gross, J. (2008). Gender differences in emotion regulation: An fMRI study of cognitive reappraisal. Group Processes and Intergroup Relations, 11(2), 143-16 2. https://doi.org/10.1177/1368430207088035

McRae, K., Gross, J., Weber, J., Robertson, R., Sokol-Hessner, P., Ray, D., Gabrieli, D., \& Ochsner, N. (2012). The development of emotion regulation: an fMRI study of cognitive reappraisal in children, adolescents and young adults. Social Cognitive and Affective Neuroscience, 7(1), 11-22. https://doi.org/10.1093/scan/nsr093

Meneses-Gaya, C., Antonio, Z., Sonia, L., \& Crippa, S. (2009). Alcohol Use Disorders Identification Test (AUDIT): An updated systematic review of psychometric properties. Psychology and Neuroscience 2 (1), 83 - 97. https://doi.org/10.3922/j.psns.2009.1.12

Mohajerin, B., Dolatshahi, B., Shahbaz, P., \& Farhoudian, A. (2013). Differences Between Expressive Suppression and Cognitive Reappraisal in Opioids and Stimulant Dependent Patients. International Journal of high risk behaviours and addiction, 2(2), 8-14. https://doi.org/10.5812/ijhrba.8514

Morris, S., Silk, S., Steinberg, L., Myers, S., \& Robinson, R. (2007). The Role of the Family Context in the Development of Emotion Regulation. Social Development, 16(2), 361-388. https://doi.org/10.1111/j.1467-9507.2007.00389.x

Mullen, K., Williams, R., \& Hunt, K. (1996). Irish descent, religion, and alcohol and tobacco use. Addiction, 91(2), 243-254. https://doi.org/10.1046/j.1360-0443.1996.9122436.x

Murphy, A., Roberts, B., Stickley, A., \& Mckee, M. (2012). Social Factors Associated with Alcohol Consumption in the Former Soviet Union: A Systematic Review. Alcohol and Alcoholism, 47(6), 711-718. https://doi.org/10.1093/alcalc/ags077

Nolen-Hoeksema, S., \& Aldao, A. (2011). Gender and age differences in emotion regulation strategies and their relationship to depressive symptoms. Personality and Individual. Differences, 51(6), 704-708. https://doi.org/10.1016/j.paid.2011.06.012

Ochsner, N., Ray, D., Cooper, C., Robertson, R., Chopra, S., Gabrieli, J., \& Gross, J. (2004). For better or for worse: neural systems supporting the cognitive down- and up-regulation of negative emotion. Neuroimage, 23(2), 483-499. https://doi.org/10.1016/j.neuroimage.2004.06.030

Parry, H. (2005). South Africa: alcohol today. Addiction, 100: 426-429. https://doi.org/10.1111/j.1360-0443.2005.01015.x

Patrick, M. E., Wightman, P., Schoeni, R. F., \& Schulenberg, J. E. (2012). Socioeconomic 
Status and Substance Use Among Young Adults: A Comparison Across Constructs and Drugs. Journal of Studies on Alcohol and Drugs, 73(5), 772-782. PMCID: PMC3410945 https://doi.org/10.15288/jsad.2012.73.772

Psirmoi, D. (2015). Underage alcohol consumers in Kenya inducted by kin, survey shows. The Standard: Retrieved from http://www.standardmedia.co.ke/article/2000180452/underage-alcohol-consumers-in-kenya-i nducted-by-kin-survey-shows

Rehm, J. (2011). Risks associated with alcohol use and alcoholism. Alcohol Research \& Health, 34(2). PMC3307043

Samokhvalov, V., Rehm, J.,\& Roerecke, M. (2015). Alcohol Consumption as a Risk Factor for Acute and Chronic Pancreatitis: A Systematic Review and a Series of Meta-analyses. EBioMedicine, 2(12), 1996-2002. http://doi.org/10.1016/j.ebiom.2015.11.023

Schulenberg, E., \& Patrick, E. (2012). Historical and developmental patterns of alcohol and drug use among college students: Framing the problem. In H. R. White \& D. Rabiner (Eds.), College student drinking and drug use: Multiple perspectives on a complex problem. New York: Guildford.

Schulte, T., Ramo, D., \& Brown, A. (2009). Gender Differences in Factors Influencing Alcohol Use and Drinking Progression Among Adolescents. Clinical Psychology Review, 29(6), 535-547. https://doi.org/10.1016/j.cpr.2009.06.003

Schnohr, C., Hojbjerre, L., Riegels, M., Ledet, L., Larsen, T., Schultz-Larsen, K., \& Gronbaek, M. (2004). Does educational level influence the effects of smoking, alcohol, physical activity, and obesity on mortality? A prospective population study. Scandinavian Journal of Public Health, 32(4), 250-6. https://doi.org/10.1080/14034940310019489

Sheppes, G., \& Meiran, N. (2007). Better late than never? On the dynamics of on-line regulation of sadness using distraction and cognitive reappraisal. Personality and Social Psychology Bulletin, 33(11), 1518-1532. https://doi.org/10.1177/0146167207305537

Smith, A., \& Kirby, D. (2001). Toward delivering on the promise of appraisal theory. In K. R. Scherer, A. Schorr., \& T. Johnstone (eds.), Appraisal processes in emotion. New York: Oxford University Press.. Stappenbeck, A., \& Fromme, K. (2014). The Effects of Alcohol, Emotion Regulation, and Emotional Arousal on the Dating Aggression Intentions of Men and Women. Psychology of Addictive Behaviors: Journal of the Society of Psychologists in Addictive Behaviors, 28(1), 1019. https://doi.org/10.1037/a0032204

Troy, S., Wilhelm, H., Shallcross, J., \& Mauss, B. (2010). Seeing the Silver Lining: Cognitive Reappraisal Ability Moderates the Relationship Between Stress and Depressive Symptoms. Emotion, 10(6), 783-795. https://do-i.org/10.1037/a0020262

Urry, L. (2009). Using reappraisal to regulate unpleasant episodes: Goals and Timing Matter. Emotion, 9(6), 782-797. https://doi.org/10.1037/a0017109

U.S. Department of Agriculture and U.S. Department of Health and Human Services (2010). 


\section{Macrothink}

International Journal of Learning and Development

ISSN 2164-4063 2018, Vol. 8, No. 3

Dietary Guidelines for Americans, 2010 (7th ed.). Washington, DC: U.S. Government Printing Office. Retrieved from: http://www.cnpp.usda.gov/sites/default/files/dietary_guidelines_for_americans/PolicyDoc.pd f.

World Cancer Research Fund/American Institute for Cancer Research. (2007). Food, Nutrition, Physical Activity, and the Prevention of Cancer: a Global Perspective.Washington DC: AICR. Retrieved from http://www.aicr.org/assets/docs/pdf/reports/Second_Expert_Report.pdf.

World Health Organization. (2014). World Health Statistics 2014. Geneva: WHO Press. Retrieved from http://www.who.int/gho/publications/world_health_statistics/EN_WHS2014_ TOC.pdf?ua=1

\section{Copyright Disclaimer}

Copyright for this article is retained by the author(s), with first publication rights granted to the journal.

This is an open-access article distributed under the terms and conditions of the Creative Commons Attribution license (http://creativecommons.org/licenses/by/4.0/). 